\title{
KINERJA PENGAWASAN INTERNAL TERHADAP INSTANSI PERANGKAT DAERAH PROVINSI KALIMANTAN TENGAH
}

(Studi di Inspektorat Provinsi Kalimantan Tengah)

\author{
Nofriandy Imanuel
}

\begin{abstract}
This research aims to determine the performance of internal supervision Inspectorate of Central Kalimantan Province. Indicators used in measuring internal supervision performance of the Central Kalimantan Provincial Device Institution namely Input (inputs), Process (process), Output (Output), Outcomes, Benefits, Impacts. This research was conducted by using qualitative descriptive method by interviewing Central Kalimantan provincial inspectorate staff. The data obtained is then processed by reduction steps, presenting the data and drawing conclusions. The informants interviewed in the Inspectorate of Central Kalimantan Province are 4 informants and 3 informants from different SOPD, with the number of informants 7 people. The results of this study explain that the performance of Inspectorate of Central Kalimantan Province in carrying out the function of guidance and supervision has been done well, based on the rules and applicable law. Internal supervision is done so that no abuse in government, coaching and supervision in PP 60 year 2008 is a preventive action. The factors that affect the performance of internal supervision of the regional apparatus of Central Kalimantan Province are: Supporting Factors: a. Ability b. Motivation c. Communication. Inhibiting Factor is the ability of human resources that limited the number of personnel of the supervisory apparatus, limited availability of budget, limited function of supervision activities in terms of performing the task of the absence of search function, seizure if SOPD is not open. Conducting internal control over the local apparatus institutions, the financial management is running well and neatly, reducing the administrative errors of the office, the work environment is orderly and effective, the regional apparatus institutions feel helped by the supervision and guidance by the Inpektorat of Central Kalimantan Province. For that through this thesis the authors provide suggestions that is expected for the Government to be able to overcome obstacles in implementing coaching and supervision, such as human resources limited personnel supervisory personnel, limited availability of budget.
\end{abstract}

Keywords: Performance, Supervision, Provincial Inspectorate

\section{PENDAHULUAN}

Pengawasan fungsional yang dilakukan oleh Inspektorat Provinsi sebagai pengawas internal Pemerintah harus optimal dan dapat menjaga integritas pemerintahan agar tidak terjadi penyelewengan dan tindakan kecurangan Pemerintahan. Karena sebagai bagian internal dalam Pemerintahan, Inspektorat Provinsi mempunyai peranan dan norma pengawasan tersendiri serta harus melaksanakannya sebagai bagian penting dalam proses pelaksanaan good 
governance. Inspektorat Provinsi mempunyai kewenangan yang secara tegas harus mengawal jalannya praktek Pemerintahan, sehingga bisa mencegah dan mendeteksi bila adanya penyelewengan oleh aparatur Pemerintah melalui pengawasan yang optimal. Keberhasilan penyelenggaraan Pemerintahan utamanya untuk mewujudkan tata Kepemerintahan yang baik ini terwujud jika sistem pengawasannya dapat berfungsi dengan baik, efektif dan efisien. Dengan demikian sistem pengawasan mempunyai peran yang strategis dalam penyelenggaraan Pemerintahan.

Adanya suatu permasalahan misalnya terbatasnya SDM, kurangnya disiplin dalam sebuah instansi pemerintahan untuk mentaati peraturan dan pelaksanaan tugas yang lainnya masih terkadang diremehkan. Keadaan tersebut disebabkan oleh tingkat kesadaran pegawai tentang tugasnya belum maksimal. sering kali pegawai lebih mengutamakan kepentingan pribadi atau golongannya. Pentingnya dorongan dalam melakukan pengawasan yang lebih baik lagi, sebab tanpa pengawasan akan mengakibatkan terjadi penyelewengan-penyelewengan.

Peningkatan kinerja pengawasan fungsional serta untuk memberikan arah dan kebijakan sesuai dengan program pemerintah untuk mewujudkan aparatur yang baik dan profesional. Peningkatan pengawasan bertujuan untuk menyempurnakan dan mengefektifkan sistem pengawasan dalam mewujudkan aparatur Negara yang bersih, akuntabel dan bebas KKN. Di samping itu juga untuk meningkatkan kualitas penyelenggaraan tugas-tugas umum Pemerintahan, pelayanan masyarakat dan pelaksanaan pembangunan serta meningkatkan bobot pengawasan melekat/pengawasan menghindari terjadinya kesalahan yang berulang-ulang. Berdasarkan latar belakang yang diangkat dari pemikiran serta dituangkan dalam tulisan diatas maka penulis tertarik untuk melakukan peneliti dan pengkajian ini diberi judul : "KINERJA PENGAWASAN INTERNAL TERHADAP INSTANSI PERANGKAT DAERAH PROVINSI KALIMANTAN TENGAH (Studi di Inspektorat Provinsi Kalimantan Tengah)".

\section{TINJAUAN PUSTAKA}

\section{Konsep Kinerja}

Secara umum pengertian kinerja merupakan terjemahan dari performance yang sering diartikan sebagai penampilan, unjuk kerja atau prestasi, kinerja pada dasarnya dapat dilihat dari dua segi, yaitu kinerja individu pegawai dan kinerja organisasi. Kinerja (performance) menurut Bernardin dan Russel (1993:379) didefinisikan sebagai catatan hasil dan keuntungan yang dihasilkan oleh fungsi pekerjaan tertentu atau aktivitas tertentu selama periode tertentu..

\section{Indikator Kinerja}

Indikator kinerja yang dimaksud LAN RI dalam Harbani Pasalong (2016:177) : "Yaitu ukuran kuantitatif/kualitatif yang menggambarkan tingkat pencapaian suatu sasaran atau tujuan yang telah ditetapkan dengan mempertimbangkan indikator masukan (inputs), keluaran (output), proses (process), hasil (outcomes), manfaat (benefits), dampak (impacts)'”. 
Proses identifikasi dan klasifikasi indikator kinerja melalui sistem pengumpulan dan pengelolaan data atau informasi untuk menentukan kinerja kegiatan, program dan kebijakan, penetapan indikator kerja harus berdasarkan pada :

a. Masukan (Input)

Segala sesuatu yang dibutuhkan agar pelaksanaan kegiatan dapat berjalan dan menghasilkan keluaran. Indikator input harus dibedakan dengan masukannya sendiri. Input adalah segala hal yang digunakan untuk menghasilkan output dan outcome. Sedangkan indikator input adalah alat yang digunakan untuk mengukur jumlah input yang digunakan untuk menghasilkan masukan dan keluaran melaksanakan kegiatan. Dengan meninjau distribusi sumber daya, suatu lembaga dapat menganalisis kesesuaian alokasi sumber daya dengan rencana strategis yang telah ditetapkan.

Tolok ukur input tidak dapat digunakan untuk menilai kinerja suatu kegiatan apabila diterapkan tidak menggunakan pertimbangan yang tepat. Besarnya input dengan tingkat keberhasilan atau kinerja suatu kegiatan memang memiliki hubungan/korelasi. Namun, tingkat korelasi ini tidak sepenuhnya tepat, karena Input yang besar tidak selalu menjamin tercapainya suatu keberhasilan pemerintah. b. Proses (Process)

Indikator ini berisi gambaran mengenai langkah-langkah yang dilaksanakan dalam menghasilkan barang atau jasa.

Indikator mengenai proses dapat dikelompokkan menjadi:

- Frekuensi proses atau aktivitas,

- Ketaatan terhadap ketentuan atau standar yang ditentukan dalam melaksanakan proses.

c. Keluaran (Output)

Indikator output harus dibedakan dengan outputnya sendiri. Output adalah segala hal yang dihasilkan oleh suatu aktivitas atau kegiatan. Sedangkan indikator output adalah alat untuk mendeskripsikan bagaimana organisasi mengelola input tersebut dalam menghasilkan output dan outcome. Dengan membandingkan output, suatu unit kerja dapat menganalisis sejauh mana kegiatan terlaksanan sesuai dengan rencana. Untuk dapat menilai kemajuan suatu kegiatan, tolok ukur output harus dikaitkan dengan sasaran-sasaran kegiatan yang terdefinisi dengan baik dan terukur. Untuk dapat menggambarkan mengenai hal tersebut, indikator kinerja output dapat dikelompokkan menjadi indikator yang menggambarkan mengenai kuantitas output, kualitas output dan efisiensi dalam menghasilkan output.

d. Hasil (Outcome)

Indikator outcome memberikan gambaran mengenai hasil aktual atau yang diharapkan dari barang atau jasa yang diproduk oleh suatu organisasi. Indikator kinerja outcome mengukur outcome yang lebih dapat dikendalikan (controllable) bagi organisasi. Untuk outcome yang melibatkan banyak pihak ataupun dipengaruhi secara signifikan oleh faktor-faktor lain di luar kendali organisasi sebaiknya diukur sebagai manfaat (benefit) atau dampak (impact).

e. Manfaat (Benefit)

Indikator kinerja ini menggambarkan manfaat yang diperoleh dari indikator hasil. Manfaat tersebut baru tampak setelah beberapa waktu kemudian, khususnya dalam jangka menengah dan jangka panjang. Indikator manfaat menunjukkan hal-hal yang 
diharapkan untuk dicapai bila keluaran dapat diselesaikan dan berfungsi dengan optimal tepat lokasi dan tepat waktu.

f. Dampak (Impact)

Indikator dampak memberikan gambaran mengenai efek langsung atau tidak langsung yang dihasilkan dari tercapainya tujuan-tujuan program. Dampak merupakan outcome pada tingkat yang lebih tinggi hingga batas tertentu. Indikator kinerja dampak, mengukur outcome yang lebih makro dan melibatkan pihak lain diluar organisasi. Karena sifatnya yang tidak dikendalikan (uncontrollable), indikator dampak boleh tidak disertai dengan target.

\section{Faktor-faktor Yang Menjadi Pendukung Kinerja}

Menurut Anwar Prabu Mangkunegara (2016:13-14) terdapat tiga faktor yang mempengaruhi kinerja, yaitu: faktor kemampuan (ability), faktor motivasi (motivation), dan faktor komunikasi. Adapun penjelasan daripada faktor kemampuan (ability), faktor motivasi (motivation), dan faktor komunikasi adalah sebagai berikut :

- Faktor kemampuan (ability), faktor ini diterangkan bahwa kemampuan (ability) karyawan atau pegawai terdiri dari kemampuan potensi $(I Q)$, dan kemampuan reality (knowledge + skill). Artinya, jika karyawan atau pegawai memiliki IQ diatas rata-rata (IQ 110-120) dengan pendidikan yang memadai untuk jabatannya dan terampil dalam mengerjakan pekerjaan sehari-hari, maka akan mudah mencapai kinerja yang diharapkan.

- Faktor motivasi (motivation), faktor motivasi ini terbentuk dari sikap (attitude) seorang guru dalam menghadapi situasi (situation) kerja. Motivasi merupakan kondisi yang menggerakkan daripada kondisi diri guru, yang terarah untuk mencapai tujuan organisasi (tujuan kerja). Sedangkan sikap mental merupakan kondisi mental yang mendorong diri guru untuk berusaha mencapai kinerja secara maksimal.

- Faktor komunikasi, yaitu Perekat dalam organisasi, menjadi penghubung mempererat rantai-rantai manajemen untuk menggerakan organisasi dalam mencapai tujuannya serta meningkatkan kinerja.

\section{Faktor-faktor Yang Menjadi Penghambat Kinerja}

Faktor-faktor yang mempengaruhi kinerja suatu organisasi dapat dijelaksan dalam Harbani Pasalong (2016:186-189), sebagai berikut :

1. Kemampuan

Pada dasarnya menurut Robbins (2002:50), adalah suatu kapasitas individu untuk mengerjakan berbagai tugas dalam suatu pekerjaan. Kemampuan tersebut dapat dilihat dari dua segi :

a. Kemampuan intelektual, yaitu kemampuan yang diperlukan untuk melakukan kegiatan mental.

b. Kemampuan fisik, yaitu kemampuan yang diperlukan untuk melakukan tugas-tugas yang menuntut stamina, kecakatan, kekuatan dan keterampilan.

2. Kemauan

Kemauan atau motivasi menurut Robbins (2002:208), adalah kesediaan untuk mengeluarkan tingkat upaya yang tinggi untuk tujuan organisasi. 


\section{Energi}

Energi menurut Jordan E. Ayan (2002:47), adalah pemercik api yang menyalakan jiwa. Tanpa adanya energi pisikis dan fisik yang mencukupi, perbuatan kreatif pegawai terhambat.

\section{Pengawasan}

Pengawasan (controlling) adalah proses pengamatan, penentuan standar yang akan dicapai, menilai pelaksanaan, dan jika perlu mengambil tindakan korektif sehingga pelaksanaan dapat berjalan sesuai dengan rencana yang telah ditetapkan sebelumnya. Tujuan utama dari kegiatan pengawasan adalah membuat kegiatan-kegiatan manajemen dinamis dan berhasil secara efektif dan efisien. Sesuai dengan perannya dalam sebuah organisasi, pengawasan memiliki beberapa fungsi. Pengawasan ialah pemeriksaan apakah sesuatu yang terjadi sesuai dengan rencana, instruksi yang dikeluarkan dan prinsip-prinsip yang telah ditentukan. Jadi tujuannya ialah untuk menunjukkan kelemahan dan kesalahan agar supaya menjadi benar dan mencegah pengulangan kesalahan, pengawasan merupakan membimbing, menertibkan, mengatur dan menguji kebenaran.

Pengawasan dapat dirumuskan sebagai proses penentuan apa yang harus dicapai, yaitu standar, apa yang sedang dilakukan yaitu pelaksanaan, menilai pelaksanaan dan bilamana perlu melakukan perbaikan-perbaikan, sehingga pelaksanaan sesuai dengan rencana, yaitu selaras dengan standar.

William H. Newman (1992:111) dalam Sukarna (1992:111), Administrative Actions menyebutkan:

"Control is assurance that the performance conform to plan. Pengawasan ialah tindakan untuk menjamin bahwa pelaksanaan sesuai dengan rencana".

\section{Inspektorat sebagai Aparat Pengawasan Internal Pemerintah (APIP)}

Pengawasan intern di lingkungan Pemerintah Provinsi/Kabupaten/Kota dilaksanakan oleh Inspektorat Pemerintah Provinsi/Kabupaten/Kota untuk kepentingan Gubernur/Bupati/Walikota dalam melaksanakan pemantauan terhadap kinerja unit organisasi yang ada di dalam kepemimpinannya. Inspektorat Provinsi menurut Peraturan Pemerintah Nomor 60 Tahun 2008 adalah adalah aparat pengawasan intern pemerintah yang bertanggung jawab langsung kepada Gubernur. Selain dari pada itu peran dan fungsi Inspektorat Provinsi dan Kabupaten/Kota secara umum diatur dalam pasal 4 Peraturan Menteri Dalam Negeri No 64 Tahun 2007. Dalam pasal tersebut dinyatakan bahwa dalam melaksanakan tugas pengawasan urusan pemerintahan, Inspektorat Provinsi dan Kabupaten/Kota mempunyai fungsi sebagai berikut:

a. Perencanaan program pengawasan

b. Perumusan kebijakan dan fasilitas pengawasan

c. Pemeriksaan, pengusutan, pengujian dan penilaian tugas pengawasan.

\section{METODOLOGI PENELITIAN}

Penelitian ini merupakan penelitian Kualitatif Deskriftif. Pada penelitian Kualitatif Deskriftif, peneliti menggambarkan fenomena empiris dengan menganalisa dan menyajikan fakta secara sistematis untuk mempermudah 
pemahaman dan penarikan kesimpulan. Dikatakan Maelong (2012:6) Penelitian Kualitatif adalah penelitian yang bermaksud untuk memmahami fenomena tentang apa yang dialami perilaku, persepsi, motivasi, tindakan dll.

Lokasi pada penelitian ini adalah di Inspektorat Provinsi Kalimantan Tengah. Dipilihnya Inspektorat Provinsi Kalimantan Tengah sebagai objek penelitian adalah karena lokasi tersebut merupakan tempat yang sesuai dengan permasalah ataupun topik yang diangkat penulis dalam melaksankan penelitian. Teknik pengumpulan data menggunakan cara observasi, wawancara, dan dokumentasi. Analisis data dilakukan dengan model interaktif dari Miles dan Huberman.

\section{HASIL PENELITIAN}

Berdasarkan hasil dari penelitian yang penulis lakukan maka ada beberapa hal yang ditemukan dalam Kinerja Pengawasan Internal Terhadap Instansi Perangkat Daerah Provinsi Kalimantan Tengah :

a. Setiap hasil pemeriksaan dilaporkan kepada Gubernur dan atas rekomendasi wajib ditindaklanjuti/diselesaikan/dipertanggungjawabkan oleh instansi pemerintah. Program yang dilakukan dalam pelaksanaan tugas pengawasan yaitu pemeriksaan reguler setiap tahun sebanyak 2 kali dan pemeriksaan probity audit yaitu penilaian (independen) untuk memastikan bahwa proses pengadaan barang/jasa telah dilaksanakan secara konsisten sesuai dengan prinsip penegakan integritas, kebenaran, dan kejujuran dan memenuhi ketentuan perundangan berlaku yang bertujuan meningkatkan akuntabilitas penggunaan dana sektor publik.

b. Proses yang dilakukan dalam pengawasan yang dilakukan aleh pengawas internal mulai dari perencanaan audit yang sudah ditetapkan sehingga tindak lanjut hasil pemeriksaan dapat dilaksanakan yaitu pemeriksaan khusus atas permintaan pihak yang ingin megetahui termasuk pengaduan masyarakat, audit operasional, keuangan, perencanaan.

c. Tindakan pencegahan yang dilakukan dengan pegawasan dilakukan agar tidak terjadi peyalahgunaan dalam pemerintahan, langkah kerja/program harus tepat agar hasil optimal. Tindakan Pencegahan dengan melalui pelaksanaan pembinaan dan peengawasan untuk mendukung ketepatan pelaksanaan tujuan tugas dan kegiatan, tindakan pencegahan untuk menghindari penyalahgunaan/kecurangan dalam melanggar hukum .

d. Hasil temuan pemeriksaan materil dan non materil, dalam LKPD (laporan keuangan pemerintah daearah) dan nilai temuan bisa memepengaruhi opini audit BPK. Hasil pengawasan dengan cermat maka semakin tidak ditemukan masalah dan tingkat kepuasan masyarakat tinggi berarti berhasil. Setiap hasil pemeriksaan dilaporkan kepada Gubernur atas rekomendasi wajib ditindaklanjuti / diselesaikan / dipertanggungjawabkan, hasil dari pemeriksaan berupa kerugian atau pemeberian teguran, peran dari pengawasan harus ditingkatkan dengan optimal agar berjalan degan baiknya Pemerintahan.

e. Bahwa manfaat dari pengawasan internal terhadap instansi perangkat daerah yaitu Administrasi kantor dan pengelolan keuangan berjalan lebih baik dan rapi sesuai dengan peraturan perundang-undangan yang berlaku, ketika pengawasan sudah 
dilakukan SOPD merasa terbantu terciptanya lingkungan kerja yang tertib, rapi dan efisien.

f. Dampak dari pengawasan internal terhadap instansi perangkat daerah yaitu peningkatan pelayanan kepada masyarakat, terciptanya Pemerintah daerah yang bersih dan beribawa.

g. Berdasarkan wawancara tersebut dan hasil penelitian dilapangan menujukan bahwa ada faktor yang mempengaruhi kinerja yaitu faktor pendukung yang terdiri dari (kemampuan, kemauan/motivasi, komunikasi) dan faktor penghambat yang terdiri dari (kamampuan dan kemauan).

Faktor pendukung yaitu adanya rasa kebersamaan dalam organisasi untuk mendorong menjadi yang lebih baik dalam melakukan pengawasan. Salah satu kunci kesuksesan pengawasan juga dibantu oleh sumber daya manusia, perlunya kemampuan aparatur yang kompoten, kerjasama yang baik akan mendukung kinerja itu berjalan dengan lancar. Kemauan/motivasi merupakan faktor pendukung dalam bekerja karena dengan kemauan yang baik kita akan mendapatkan hasil yang ingin dicapai. Komunikasi sebagai pendukung kinerja seseorang agar berjalan dengan baik maka seharusnya komunikasi meningkat seiring lamanya dia bekerja dari yang tidak tahu menjadi tahu, dari yang tidak bisa menjadi bisa.

Faktor penghambat yaitu Kemampuan SDM dengan terbatasnya jumlah personil aparat pengawasan, terbatasanya ketersediaan anggaran dalam pelaksanaan kegiatan pengawasan, juga yang meghambat kinerja karena tidak adanya fungsi pengeledahan, penyitaan apabila SOPD tidak terbuka.

\section{PENUTUP}

\section{Kesimpulan}

Berdasarkan penelitian yang penulis lakukan maka dapat disimpulkan:

a. Setelah melakukan penelitan tentang Kinerja Pengawasan Internal Terhadap Instansi Perangkat Daerah di Provinsi Kalimantan Tengah, data yang sudah diperoleh dan diolah pada bab sebelumnya dapat disimpulkan bahwa Kinerja Inspektorat Provinsi Kalimantan Tengah dalam melaksanakan fungsi pembinaan dan pengawasan sudah dilakukan dengan baik, berdasarkan peraturan dan undang-undang yang berlaku. Kinerja pengawasan internal Inspektorat Provinsi Kalimantan Tengah sudah berdasarkan Indikator yang digunakan dalam mengukur kinerja pengawasan internal terhadap instansi perangkat daerah Provinsi Kalimantan Tengah yaitu Masukan (inputs), Proses (process), Keluaran (output), Hasil (outcomes), Manfaat (benefits), Dampak (impacts).

b. Adapun faktor-faktor yang mempengaruhi kinerja pengawasan internal terhadap instansi perangkat daerah Provinsi Kalimantan Tengah yaitu: Faktor Pendukung: a. Kemampuan b. Motivasi c. Komunikasi. Faktor Penghambat yaitu Kemampuan SDM yang terbatasnya jumlah personil aparat pengawas, terbatasnya ketersediaan anggaran, terbatasnya fungsi pelaksanaan kegiatan pengawasan dalam hal melakukan tugas tidak adanya fungsi pengeledahan, penyitaan apabila SOPD tidak terbuka. 
Dilakukannya pengawasan internal terhadap instansi perangkat daerah maka pengelolan keuangan berjalan degan baik dan rapi, mengurangi kesalahan administrasi kantor, lingkungan kerja yang tertib dan efektif, instansi perangkat daearah merasa terbantu dengan adanya pengawasan dan pembinaan oleh Inpektorat Provinsi Kalimantan Tengah.

\section{Saran}

Berdasarkan hasil penelitan dan pembahasan yang dilakukan mengenai kinerja pengawasan internal terhadap instansi perangkat daerah Provinsi Kalimantan Tengah, penulis menemukan beberapa aspek penting yang dinilai perlu untuk diperhatikan lagi, dalam hal yang menjadi kendala/penghambat dalam melaksanakan pembinaan dan pengawasan terhadap instansi perangkat daearah, untuk itu melalui skripsi ini penulis memberikan saran yaitu Perlu ditingkatkannya koordinasi dan optimalisasi tindakan preventif terhadap SOPD, diharapkan bagi pemerintah untuk bisa mengatasi kendala dalam melaksanakan pembinaan dan pengawasan, seperti SDM yang terbatasnya jumlah personil aparat pengawas, terbatasnya ketersediaan anggaran, terbatasnya fungsi pelaksanaan kegiatan pengawasan dalam hal melakukan tugas tidak adanya fungsi pengeledahan, penyitaan apabila SOPD tidak terbuka.

\section{DAFTAR PUSTAKA}

A. Anwar Prabu Mangkunegara. 2006. Evaluasi Kinerja SDM. Bandung: PT. Refika Aditama.

Ayan, E. Jordan. 2002. Bengkel Kreativitas. Dalam Harbani Pasalang. Teori Administrasi Publik. Makasar. Makasar : CV. Alfabeta.

Bernardin, H. John \& Joyce E. A. Russell, 1993, Human Resource Management. Singapore: McGraw Hill Inc.

Dunn, William N. 2003. Pengantar Analisa Kebijakan Publik Edisi Kedua, Yogjakarta: Gadjah Mada University Press.

Dwiyanto, Agus. 2006. Penilain Kinerja Organisasi Pelayanan Publik. Dalam Harbani Pasalong. Teori Administrasi Publik. Bandung: CV Alfabeta.

Gibson. 1997. Organisasi Prilaku Struktur Proses. Dalam Harbani Pasalang. Teori Administrasi Publik. Makasar. Makasar : CV. Alfabeta.

Inspektorat Provinsi Kalimantan Tengah. 2016. Diambil 1 Maret 2017, dari situs Word Wide Web http://www.inspektoratkalteng.org/web/web/pages/1/profil-kantor.

Koontz, Harold. William. 1959. Principles Of Management. Dalam Sukarna. Dasar-dasar Manajemen. Bandung: CV Mandar Maju.

Maelong Lexy J. 2012. Metodologi Penelitian Kualitatif. Bandung: PT. Remaja Rosdakarya.

Mardiasmo. 2005. Akuntansi Sektor Publik Edisi 2. Yogjakarta: Andi. 
Miles, M.B. dan Huberman, A.M. 1992. Analisis Data Kualitatif: Buku Sumber Tentang Metode Metode Baru. Jakarta: UIPress.

Newman,H. William, Dalam Sukarana. Dasar-dasar Manajemen. Bandung: CV Mandar Maju.

Pasalong, Harbani. 2013. Teori Administrasi Publik. Makasar : CV. Alfabeta.

Peraturan Daerah Provinsi Kalimantan Tengah Nomor 4 Tahun 2016 Tentang Pembentukan Dan Susunan Perangkat Daerah

Peraturan Menteri Dalam Negeri Nomor 64 Tahun 2007 Tentang Pedoman Teknis Organisasi Dan Tata Kerja Inspektorat Provinsi Dan Kabupaten/Kota

Peraturan Pemerintah Nomor 60 Tahun 2008 Tentang Sistem Pengendalian Intern Pemerintah

Robbin. 2002. Teori Organisasi. Dalam Harbani Pasalang. Teori Administrasi Publik. Makasar. Makasar : CV. Alfabeta.

Serdamayanti. 2007. Manajemen Sumber Daya Manusia, Reformasi Birokrasi dan Manajemen Pegawai Negeri Sipil(ce. Bandung: PT Refika Aditama.

Strauss.G, Sayles.L. 1990. Manajemen Personalia. Dalam Harbani Pasalang. Teori Administrasi Publik. Makasar. Makasar : CV. Alfabeta.

Terry, G.R. Principles of Management. Dalam Sukarana. Dasar-dasar Manajemen. Bandung: CV Mandar Maju.

Timpe A. Dale. 1992. Kinerja. Dalam A. Anwar Prabu Mangkunegara. Evaluasi Kinerja SDM Bandung: PT. Refika Aditama.

Timpe A. Dale. 1992. Kinerja. Jakarta: PT.Gramedia.

Widodo, Joko. 2006. Membangun Birokrasi Berbasisi Kinerja. Dalam Harbani Pasalang. Teori Administrasi Publik. Makasar. Makasar : CV. Alfabeta. 